\title{
Efficient Digital Practices of Supplemental Vocational Education
}

\author{
Vladimir Vasilievich Afanasyev ${ }^{1 *}$, Ilya Vladimirovich Afanasyev ${ }^{2}$, Svetlana Mikhailovna \\ Kunitsyna $^{3}$, and Mikhail Petrovich $\mathrm{Nechaev}^{3}$ \\ ${ }^{1}$ Moscow City University, Institute of Pedagogy and Psychology of Education, Moscow, Russia \\ ${ }^{2}$ Financial University under the Government of the Russian Federation, Moscow, Russia \\ ${ }^{3}$ Academy of Social Management, Moscow, Russia
}

\begin{abstract}
Increasing importance and expansion of spectrum of functions of continuing education system in the era of digitalization will facilitate steady vocational and personal development of teachers. Searching for new pedagogical designs of supplemental vocational education can be considered as a force of sustainable development of occupational quality of teachers. In this context, the main aim of this work is to present one of significant constructs of such design of the system of supplemental vocational education: educational e-course. The main research methods are theoretical analysis of psychological and pedagogical, sociological and philosophical sources, analysis of actual data. The obtained result is the structure of educational e-course developed with consideration for decease in teachers' labor consumption with obligatory preservation of education quality. Expert appraisal of the presented digital construct is based on reviews by teachers of educational entities, where advantages of electronic approach to development of educational course are mentioned and overall efficiency of such education is demonstrated.
\end{abstract}

\section{Introduction}

Nowadays it is obvious that digitalization covers absolutely all spheres of human activities. The system of supplemental vocational education is not an exception $[1,2]$. In its frames numerous educational entities operate, including private companies, developing educational e-courses of skills upgrading for teachers with wide range of topics. Sometimes consumers can ask: Which course should be selected?

Theoretically, a consumer (a teacher) should select subject of skills upgrading courses on the basis of own occupational deficits [1]. In practice we deal with the fact that a teacher is rather time bounded, hence, the main aim is to acquire a certificate of advanced training. Obviously, the education quality can be deteriorated.

Academy of Social Management of Moscow City Pedagogical University developed the structure of e-courses oriented at decrease in teachers' labor consumption and high education quality.

\footnotetext{
* Corresponding author: vvafv@yandex.ru
} 


\section{Methods}

The following methods were used: theoretical analysis of psychological and pedagogical, sociological and philosophical sources, analysis of actual data.

\section{Results}

School reality is rapidly varying, while modern teacher education does not have time to adapt to the new environment. There is a gap between the existing demands of executional entities and quality of teacher training.

Analysis of modern psychological and pedagogic studies makes it possible to conclude that in the Russian teaching system, the significance of new system of continuing teacher education increases, allowing to provide personal and vocational development of each teacher. The existing system of teacher training at pedagogical higher school is not variable, it does not satisfy professional shortages [1, 3-8].

Therefore, it becomes necessary to update the system of supplemental vocational education. Its design should be updated in order to provide skills development.

Methods of e-learning provide wide opportunities to eliminate professional shortages and personal development of teachers.

Implementation of e-learning into educational process was discussed by Russian researchers (Andreev, Vaindorf-Sysoeva, Gorbunova, Panyukova, Polat, Chernobai) [9].

Andreev considers distance learning as "an oriented process of interactive communication of teachers and students between themselves and with teaching tools, invariant to location in space and time and implemented in specific didactic system" [1].

Vaindorf-Sysoeva described development of electronic didactics, considering it as a theory of learning in virtual educational environment [2].

Gorbunova developed various models of e-learning in the system of skills upgrading of teachers [10].

Komleva, Lebedev, and Molchanov developed the concept of development of information and educational milieu of higher school $[9,11]$.

Polat believes that e-learning should be considered as advanced teaching technologies [9, 12-14]. Theoretical and practical aspects of reasonable application of information technologies in educational entities are considered by Panyukova.

It follows from review of publications devoted to e-learning in education, including supplemental vocational education, that e-learning should be considered as a new educational paradigm [9].

Let us consider an efficient model of such e-course.

E-course is a learning resource aimed at implementation of supplemental vocational program of skills upgrading using electronic support, including modules of online learning and individual work in interactive educational milieu of the course.

The course structure is comprised of 12 six-hour modules, including two modules of resident training, modules of online learning, and module of individual work in interactive educational milieu of the course.

Sequence and terms of module learning period are preset.

Variants of course learning are stipulated. On the basis of results of input testing (on the initiative of a student and in agreement with the course instructor), the students that have completed $75 \%$ of test can replace three modules, including individual work (18 h in total), with personal assignment to describe and to present own practice with innovative procedures of education, organizational forms, control tools, etc. 
Materials of the classes should be variable and provide opportunity for students to select assignments for individual work with consideration for professional shortages and demands of students.

Elements and modules of e-course:

Information element:

- Educational program

- Curriculum

- Category of students

- Summary

- Intelligent card

- Course presentation (video clip or audio presentation)

- Information about the authors of the course (with photos)

Introductory module - module of resident learning:

- should contain brief summary or plan of resident classes as course elements,

- should have a test of input diagnostics with at least 20 questions.

Learning session includes execution of input tests by students in computer lab or by means of own mobile devices in any classroom with Wi-Fi Internet access.

During the session the students are introduced by means of specially selected methods, express surveys, professional communication in light format.

The students are instructed regarding techniques and technologies of learning in the applied e-learning environment.

The introduction results in coordinated selection of individual education route by a single student.

During the introductory session, the issues of course methodology are discussed, important theoretical provisions and other issues are highlighted according educational program.

Each learning module should be finished by control of presented learning material:

- in the form of intermediate test (four tests per a course of $72 \mathrm{~h}$ containing five questions);

- in the form of essays;

- in the form of survey (at least 7 questions);

- inspection test or other form of control (optional supplements).

Attestation module - resident:

- should contain final test of 30 questions in order to perform testing as a form of final attestation;

- methodological recommendations for development of qualifying works,

- template of expert worksheet;

- collection of qualifying works: projects of application of course materials in own professional practice in the form of video clips or presentations;

- methodological recommendations on preparation of materials for presentation of individual teaching practice by student choice;

- time schedule for final conference (optional form of final attestation);

- time schedule of integrated testing (optional form of final attestation);

Online learning modules are based on educational program.

Lectures as a type of learning sessions included into educational program should be presented in format of video-lecture, lecture-presentation, hypertext, and contain assignment for interaction between the students using interactive elements: forum, chat, WiKi, and a set of assignments for joint work. Each lecture should be accompanied by summary and plan.

The following lectures are included in the course content: 
- video lectures $15 \backslash 15 \backslash 15$ with methodological instructions on working with video record of the lecture, containing assignments and comments: at least one video lecture per course;

- lectures comprised of hypertext with assignments and questions to the text, completed with updated list of main references: at least one lecture in the mentioned format per course;

- lecture-presentation with comments and accompanying audio: at least one lecture per course;

- lecture-slide;

- and others.

Online learning sessions can be designed as follows:

- in the form of webinar (online or offline) with methodological recommendations and/or instructions, assignments for working with the webinar recording; with plan and assignments for online webinar; notification about it is published in the course environment as news;

- as a master class in video format with methodological recommendations and/or instructions, assignments for working with the master class recording;

- as student or scientific conference in video format with methodological recommendations and/or instructions, assignments for working with the conference recording;

- as practical training.

Practical lessons in the structure of online learning sessions should contain assignment for interaction between the students by means of interactive elements:

- Forum

- Chat

- WiKi and a set of assignments for joint work.

Practical learning sessions should be accompanied by plan, procedural instructions. They can have supplemental materials presented by virtual labs, educational computer games, and other educational e-courses (EEC) in the format of audio and video recordings, presentations, including online quests, links to online simulators, providing execution of practical works using unified information systems (UIS) for practical assignments (for instance, Pedagog UIS with e-versions of description of educational and teaching practices, or UIS School portal of Moscow oblast containing EEC of various levels and purposes).

Studying best pedagogic practice.

Analysis of best pedagogical practice (BPP) of Moscow oblast should be an obligatory element of the course, which could be supplemented by educational practices of other regions of the Russian Federation on the same topics.

Studying BPP materials should be included into the content of at least two modules. BPP studying can be included into any online learning class. BPP is presented by the following materials:

- Summary card,

- BPP data card with hyperlinks to websites of objects of study, BPP video clip.

Mandatory materials can be accompanied by supplemental materials: presentations, multimedia ID and cards, and others.

Library of materials:

- monographs

- articles

- teaching packages

- and other works.

The course library can be updated by means of addition of materials recommended and presented by students. 


\section{Discussion}

Surveys of teachers and principals of educational entities of Moscow oblast [15] have demonstrated that application of this model has the following advantages:

- makes the schedule of training flexible and convenient;

- allows to preserve education quality at moderate teachers' labor consumption;

- education can be conducted in any place using any device;

- the course materials can be always available for teacher;

- interaction with teacher is enabled.

\section{Conclusion}

Application of e-learning in the system of supplemental vocational education brings it to qualitatively new level, provides free and open access for each student to continuing development of occupational quality with consideration for his/her interests, capabilities, and educational demands.

\section{References}

1. A.A. Andreev, The didactic foundations of distance learning (Rao, Moscow, 1999)

2. M.E. Vaindorf-Sysoeva, Methods of distance learning (Urait, Moscow, 2018)

3. K. Schwertner, Trakia J. Sci. 15(1) 388-393 (2017)

4. H.L. Tay, S.W.K. Low, Int. J. Productiv. Perform. Manag. 66(5) 680-694 (2017)

5. R. Ullah, A. Khalid, E. Todeva, The Triple Helix Assoc. Mag. 6(2) 21-22 (2017)

6. W. Viryasitavat, L.D. Xu, Z. Bi, A. Sapsomboon, , J. Intell. Manuf. 1-12 (2018)

7. J. Derry, J. Philos. Educ. 54(1) 5-22 (2020)

8. H. Fjørtoft, Comp. Educ. 152 (2020)

9. M.P. Nechaev. Sci. Sup. Syst. Adv. Train. 3(40) 58-67 (2019)

10. L.N. Gorbunova, Inform. Educ. 7 91-95 (2004)

11. N.V. Komleva, S.A. Lebedev, A.S. Molchanov, Open Educ. 4(111) 58-61 (2015)

12. G. Polizzi, Comp. Educ. 152 (2020)

13. H. Fjørtoft, Comp. Educ. 152 (2020)

14. A.M. Bredy, J. Philos. Educ. 54(1) 183-200 (2020)

15. Listener reviews. New Electronic Continuing Education System 2020. Available at: http://eor.asou-mo.ru/index.php/2018-07-17-07-46-29 